\title{
Interfacially synthesized PAni-PMo12 hybrid material for supercapacitor applications
}

\author{
ARUMUGAM MANIVEL ${ }^{\mathrm{a}}$, ABDULLAH M ASIRI ${ }^{\mathrm{b}}$, KHALID AHMAD ALAMRY $^{\mathrm{b}}$, \\ TERESA LANA-VILLARREAL ${ }^{\mathrm{c}}$ and SAMBANDAM ANANDAN ${ }^{\mathrm{a}, *}$ \\ ${ }^{a}$ Nanomaterials and Solar Energy Conversion Lab, Department of Chemistry, National Institute of Technology, \\ Tiruchirappalli 620 015, India \\ ${ }^{\mathrm{b}}$ The Centre of Excellence for Advanced Materials Research, King Abdulaziz University, Jeddah 21413, \\ P.O. Box 80203, Saudi Arabia \\ 'Institut Universitarid’ Electroquímica, Departament de Química Física,Universitatd’ Alacant, Apartat 99, \\ E-03080 Alacant, Spain
}

MS received 25 May 2013; revised 24 July 2013

\begin{abstract}
The concept of interfacial polymerization is utilized for the synthesis of polyaniline-phosphomolybdate (PAni-PMo12) molecular hybrids and it is well characterized. The electrical conductivity of the synthesized hybrid materials increases with increase in PMo12 wt\%. The synthesized hybrid materials are evaluated as the active electrode materials for supercapacitor application. Cyclic voltammetric studies of the hybrid-modified electrode shows broad parallelogram-shaped peak as an evidence for pseudo-capacitive behaviour. The galvanostatic charge-discharge studies enlighten that interfacially synthesized hybrid materials loaded with PMo12 show relatively enhanced specific capacitance values than PMo12 free samples.
\end{abstract}

Keywords. Hybrid materials; polyaniline; phosphomolybdic acid; interfacial polymerization; supercapacitor.

\section{Introduction}

Organic-inorganic hybrid systems have attracted widespread attention in the domain of material science, because of the interest in the synergy between the organic and inorganic components, and in the opportunity to use the fundamental properties of both (Sanchez et al 2005, 2010). The structure-controlled combination of organic and inorganic units have become an emerging area of research in the development of multifunctional materials (Sanchez et al 2005, 2010). The chemical strategies offered by the coupling of organic and inorganic components through soft chemistry processes utilizing functional building blocks through an intelligent and tuned coding way, to develop a new vectorial chemistry, which can offer versatile access to the hybrid property (Sanchez et al 2001; Dolbecq et al 2010; Nisar et al 2010). Among the many possible categories of organic components, conducting organic polymers (COPs) constitute a particular and attractive group due to their unique recipe of conducting, electroactive and polymeric properties (Otero et al 2000; Malinauskas 2001). Polyaniline (PAni) is one such conducting polymer that has been extensively studied

\footnotetext{
*Author for correspondence (sanand99@yahoo.com, sanand@nitt.edu)
}

for the construction of hybrid materials due to its properties of interest such as lightweight, low cost, good environmental stability and tunable physicochemical properties for various applications (de Leeuw et al 1997; Gurunathan and Trivedi 2000; Palaniappan 2001; Gurunathan et al 2003; Choi et al 2005; Gharibi et al 2006, 2011; Bhadra et al 2009; Huang et al 2011; Mahanta et al 2011; Matsuguchi and Asahi 2011). Indeed, most of the studied and documented hybrids of polyaniline are composed of oxides of various elements across the periodic table (Ganesan and Gedanken 2008; Radhakrishnan et al 2009a,b, 2011) to keep their integrity and activity in addition to benefit their conducting and polymeric properties.

Currently, PAni and polyoxometalates (POMs)-based hybrids have attracted much interest. Because of the welldefined structure of POMs and their reversible electron shuttling and photoelectrochemical properties make them as structural and functional models for nanometric oxide particles (Lira-Cantu and Gomez-Romero 1998; Gomez-Romero et al 2003; Kulesza et al 2005; Emmanuel et al 2009; Anandan and Manivel 2011), may perhaps be used in technological applications, for example, in capacitors (Lira-Cantu and Gomez-Romero 1998; Gomez-Romero et al 2003), electrocatalytic systems (Kulesza et al 2005; Manivel and Anandan 2011), etc. Pristine PMo12 is ignored as active compound for 
solid-state applications, because of its large solubility in solvent water (Cuentas-Gallegos et al 2007). In addition, the poor solubility of conducting polyaniline minimizes the leaching properties of POMs and affords a good accessibility to the electrochemical properties (LiraCantu and Gomez-Romero 1998; Gomez-Romero et al 2003; Kulesza et al 2005; Emmanuel et al 2009; Manivel and Anandan 2011). In POM families, Keggin-type, phosphomolybdic acid (PMo12) is an appropriate choice as inorganic counterpart due to its advantages such as high stability in acidic media, including exceptionally high proton conductivity and having a large effective surface area; and readily available active $\mathrm{MoO}_{6}$ octahedra present towards outside (Fan et al 2010). Hybrid polyanilinePOMs can be formed by several ways that includes direct mixing (Lira-Cantu and Gomez-Romero 1998), layer by layer network assembly (Kulesza et al 2005), vapour phase synthesis (White and Slade 2003), electrochemical deposition (Lira-Cantu and Gomez-Romero 1998; Sine et al 2003), etc. However, most of these procedures are derived from general polyaniline synthesis procedures available in literature. Among the available variety of approaches for the chemical synthesis of polyaniline, interfacial polymerization is a reliable method for the preparation of nanostructured polyaniline (Zhang et al 2004; Huang 2006; Xing et al 2008). In this method, monomer aniline and dopants were polymerized at the interface between two immiscible liquids to get a polyaniline in a controlled structure (Zhang et al 2004; Huang 2006; Xing et al 2008).

Hence, in this paper, we attempted to implement the interfacial polymerization approach for the synthesis of PAni-PMo12 hybrid material. Synthesized hybrid PAniPMo12 materials were well characterized and evaluated as electrode material for supercapacitor application. This hybrid electrode benefits mutually from Faradaic contribution of both the components and the presumed homogeneity and distribution of POM ions on PAni, a condition that leads to greater charge delocalization and enhanced conductivity. Hence, it could be a promising material for supercapacitor electrodes.

\section{Experimental}

\subsection{Materials}

Aniline from Rankem Chemicals (India) was distilled under vacuum prior to use. Phosphomolybdic acid $\left(\mathrm{H}_{3} \mathrm{PMo}_{12} \mathrm{O}_{40}\right)$ was purchased from Aldrich Chemicals and used without further purification. Potassium chloride $(\mathrm{KCl})$, ammonium persulphate $\left(\left(\mathrm{NH}_{4}\right)_{2} \mathrm{~S}_{2} \mathrm{O}_{8}\right)$, potassium ferricyanide $\left(\mathrm{K}_{3}[\mathrm{Fe}\right.$ $\left.\left.(\mathrm{CN})_{6}\right]\right)$ and chloroform $\left(\mathrm{CHCl}_{3}\right)$ were obtained from Merck Chemicals. Unless otherwise specified, all the reagents used were of analytical grade and the solutions were prepared using Millipore water.

\subsection{Instrumentation}

UV-Vis absorption spectra were recorded with a T90+ double beam UV-Vis spectrophotometer (PG Instruments, United Kingdom). Fourier transform infrared (FTIR) spectra of the samples (with $\mathrm{KBr}$ powder pellets) were recorded on a Paragon 500 spectrometer from Perkin Elmer (USA). The conductivity of the synthesized hybrid was measured by the four-probe method with a Keithley nano-voltmeter (USA). Thermogravimetric analysis (TGA) experiments were performed with a TA instruments (UK) model SDT Q600 via heating under air at $20^{\circ} \mathrm{C} / \mathrm{min}$. X-ray diffraction analysis of the hybrid materials were performed using Rigaku diffractometer (CuK $\alpha$ radiation), Japan. The surface morphology of the samples was recorded using HITACHI scanning electron microscope. The electrochemical experiments were carried out on an Autolab PGSTAT 302N (The Netherlands) electrochemical system. A conventional three-electrode assembly was used for cyclic voltammetric measurements and charge-discharge studies. A homemade $1 \mathrm{~cm}^{2}$ stainless steel (SS) and platinum foils were employed as the working electrode and counter electrode, respectively. Ag/ $\mathrm{AgCl}$ electrode purchased from BASi (USA) and used as reference electrode. The solutions were thoroughly degassed by slow bubbling of nitrogen for at least $15 \mathrm{~min}$ prior to measurements. All the experiments were carried out at room temperature $\left(25 \pm 2{ }^{\circ} \mathrm{C}\right)$.

\subsection{Interfacial synthesis of PAni-PMo12 hybrid materials}

The polyaniline-phosphomolybdate hybrid materials were synthesized through the interfacial polymerization as follows. A biphasic interface was formed between the aqueous solution of $0.011 \mathrm{M}$ ammonium peroxidisulphate $(150 \mathrm{~mL})$ containing calculated amount of phosphomolybdic acid (0, 0.05, 0.1, 0.25, 0.5 and $1 \mathrm{wt} \%)$ and $150 \mathrm{~mL}$ chloroform containing $0.01 \mathrm{M}$ freshly distilled aniline. The resulting two-phase system was covered with aluminium foil to minimize solvent evaporation and left undisturbed for about $12 \mathrm{~h}$. The polymerization reaction was noticed with change in colour of the aqueous phase from pale yellow to dark green. Later, reaction mixture was filtered under suction to get a solid dark green PAniPMo12 precipitate. The precipitate was continuously washed several times with Millipore water and finally with acetone and vacuum dried at $50{ }^{\circ} \mathrm{C}$.

\subsection{Electrode preparation}

The synthesized PAni-PMo12 hybrid materials were modified on the stainless steel current collectors $\left(1 \mathrm{~cm}^{2}\right)$ by the following procedures. Hybrid-modified electrode were prepared using polyvinylidene fluoride (PVDF, 
$10 \mathrm{mg}$, Fluka) as binder, activated carbon (10 mg, Fluka) as diluter and the active hybrid materials as conductor (80 mg). First, PVDF was dissolved in $N$-methylpyrrolidone (NMP) solvent and other ingredients were thoroughly mixed into it by manual grinding in a mortar. The resulting slurry was uniformly coated on the SS electrode and dried at $50{ }^{\circ} \mathrm{C}$ for $24 \mathrm{~h}$.

\section{Results and discussion}

\subsection{Characterization of PAni-PMo12 hybrid materials}

The polyaniline-phosphomolybdate (PAni-PMo12) hybrid materials with different amount of PMo12 have been synthesized through the simple interfacial synthesis procedure. The formation of PAni-PMo12 hybrid materials in the presence of calculated amount of phosphomolybdic acid $(0,0.05,0 \cdot 1,0.25,0.5$ and $1 \mathrm{wt} \%)$ was confirmed and analysed by various spectroscopic methods.

Figure 1 shows FT-IR spectra of PAni synthesized with and without PMo12 through interfacial polymerization method. Pure PAni without PMo12 shows characteristic band at $1563 \mathrm{~cm}^{-1}$ (marked as *) arise mainly from both $\mathrm{C}=\mathrm{N}$ and $\mathrm{C}=\mathrm{C}$ stretching vibrations of the quinoid di-imine unit, whereas the band around $1489 \mathrm{~cm}^{-1}(\diamond)$ is attributed to the $\mathrm{C}=\mathrm{C}$ ring stretching of the benzenoid diamine unit (figure 1a). The bands around 1297 (•) and $800 \mathrm{~cm}^{-1}$ (O) can be assigned to $\mathrm{C}-\mathrm{N}$ stretching of the secondary aromatic amine and an aromatic $\mathrm{C}-\mathrm{H}$ out-ofplane bending mode, respectively. PAni synthesized with various concentrations of PMo12 $(0.05,0 \cdot 1,0 \cdot 25,0.5$ and $1 \mathrm{wt} \%)$ shows almost similar stretching frequencies as that of pure PAni (figure 1b-f). However, new absorption peaks appear at $864 \mathrm{~cm}^{-1}(\boldsymbol{\square}), 965 \mathrm{~cm}^{-1}(\square)$ and

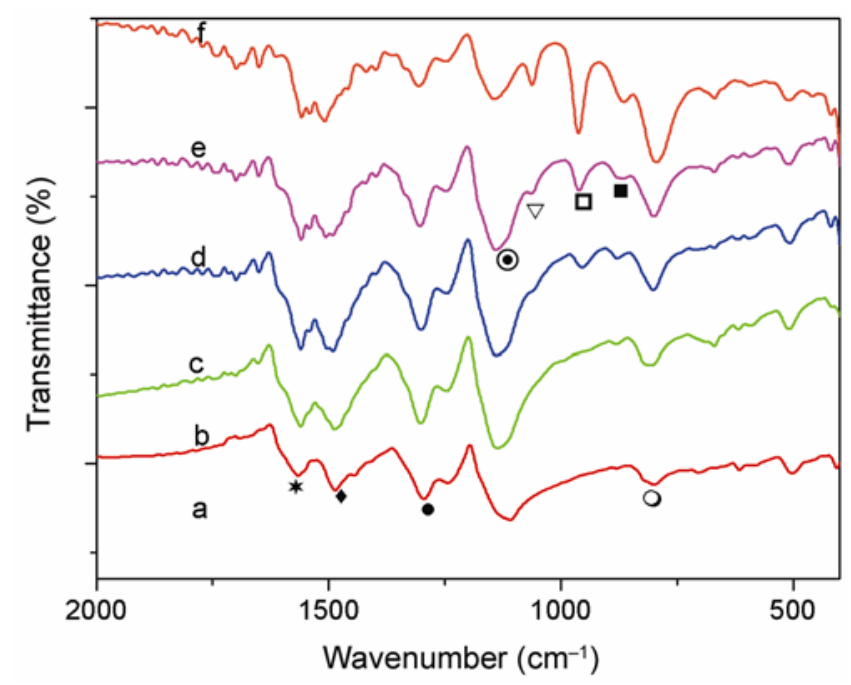

Figure 1. FT-IR spectra for interfacially synthesized PAniPMo12 hybrid materials at different concentrations of PMo12. $(\mathrm{a}-\mathrm{f})=0,0 \cdot 05,0 \cdot 1,0 \cdot 25,0.5$ and $1 \mathrm{wt} \%$ of PMo12.
$1067 \mathrm{~cm}^{-1}(\nabla)$ signifies the presence of PMo12 in the PAni-PMo12 hybrid material. The peak at $864 \mathrm{~cm}^{-1}$ may be attributed to edge sharing of Mo-O-Mo. The terminal $\mathrm{Mo}=\mathrm{O}$ stretching vibration of PMo12 could be assigned for $965 \mathrm{~cm}^{-1}$ peak. The clear predominant peak at $1067 \mathrm{~cm}^{-1}$ is due to $\mathrm{P}-\mathrm{O}$ vibrations of PMo12 (LiraCantu and Gomez-Romero 1998; Anandan and Manivel 2011) which goes on increasing with increase in the weight\% of PMo12. Further increase in intensity of peak at around $1138 \mathrm{~cm}^{-1}(\odot)$ is noticed, while increase in the weight\% of PMo12 may be due to protonation of polyaniline backbone (Chiang and MacDiarmid 1986; Tang et al 1988). Further, this band has been related to the high degree of electron delocalization in PAni and as well as leads to strong interaction with PMo12 (Colomban et al 1994; Hasik et al 2002).

The study of the electronic structure of the protonated polyaniline-based hybrid material is complicated due to the simultaneous presence of different structures. However, the chain conformation of polyaniline plays an important role in its properties (Ghadimi et al 2002). We have investigated this dependence in our samples using UV-Vis spectroscopy. UV-Vis absorption spectra of synthesized PAni-PMo12 hybrid material with different concentrations of PMo12 (0, 0.05, 0.1, 0.25, 0.5 and $1 \mathrm{wt} \%)$ show two absorption peaks, one around $330 \mathrm{~nm}$ and the other at $630 \mathrm{~nm}$ representing the formation of emaraldine form of polyaniline as described in the literature (Ghadimi et al 2002; Fauziah et al 2009) (figure 2). The absorption peak at $330 \mathrm{~nm}$ is arising from excitation of the benzene segment including amine structures in polyaniline, whereas the absorption peak at $630 \mathrm{~nm}$ arising from the quinoid structure including the imine moiety. With increasing concentration of PMo12, there was no changes observed in absorption band positions, but

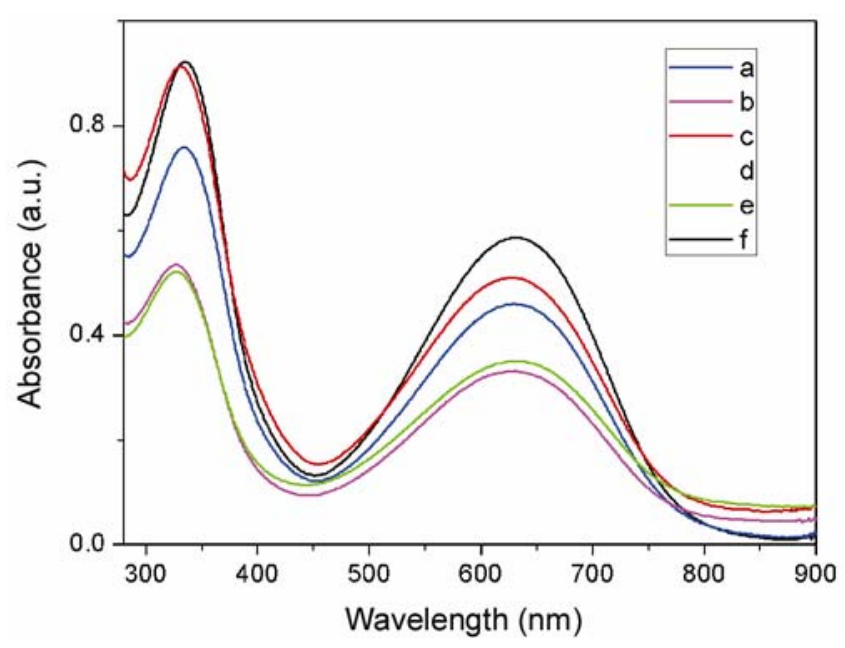

Figure 2. UV-Vis absorbance spectra of interfacially synthesized PAni-PMo12 hybrid materials at different concentrations of PMo12. $(\mathrm{a}-\mathrm{f})=0,0 \cdot 05,0 \cdot 1,0 \cdot 25,0 \cdot 5$ and $1 \mathrm{wt} \%$ of PMo12. 
increased protonation of nitrogen atoms in imine groups (Chiang and MacDiarmid 1986; Tang et al 1988) aid the nitrogen and its neighbouring quinoid ring become a semiquinoid radical cation, causing a decrease in the exciton absorption peak intensity around $630 \mathrm{~nm}$ that is evident in the increase in doping of PMo12 on the polyaniline.

X-ray diffraction (XRD) analysis was performed to identify the formation of PAni-PMo12 hybrid material and their crystallinity as a function of different wt\% of PMo12 component (0-1 wt\%) (figure 3a-f). XRD patterns of hybrid material without PMo12 (figure 3a) shows two broad peaks at $2 \theta$ angles around 20 and $26^{\circ}$. These peaks are the characteristics of emarildine form of pure PAni, which exhibits a highly-ordered structure with high $\pi$-conjugated quasi amorphous system (Ryu et al 1999). The diffraction patterns of prepared hybrid materials in the presence of $0.05,0.01$ and $0.25 \mathrm{wt} \%$ PMo12 shows no characteristic diffraction peaks of PMo12 which may be due to finely dispersed PMo12 in the polymer matrix and thus, the formed hybrid is also amorphous in nature. In addition, broad peaks noticed also indicate the conformation of complete homogeneity and compatibility among the components of the hybrid. Further increase in PMo12 concentrations $(0.5$ and $1 \mathrm{wt} \%)$ results in appearance of a more sharply-defined diffraction patterns of PMo12 (Gong et al 2002) which indicate that the higher encapsulation of PMo12 in the polyaniline matrix affected the arrangements of PMo12 in polyaniline chains and in turn affects the amorphocity or increases the crystallinity.

Scanning electron microscopic studies were also performed to study the effect of PMo12 concentration on the surface morphology of the interfacially synthesized

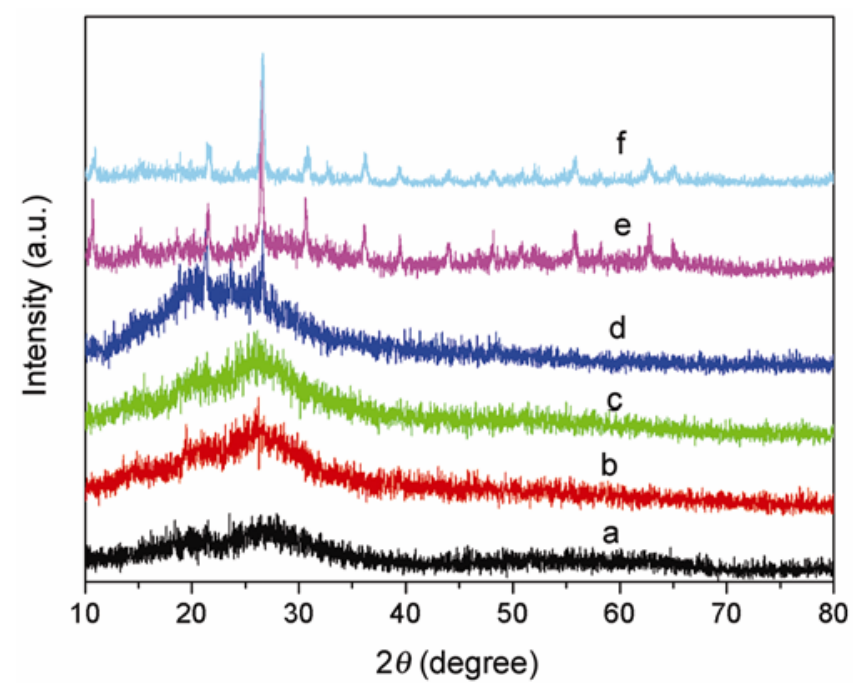

Figure 3. XRD patterns of interfacially synthesized PAniPMo12 hybrid materials at different concentrations of PMo12. $(\mathrm{a}-\mathrm{f})=0,0 \cdot 05,0 \cdot 1,0 \cdot 25,0.5$ and $1 \mathrm{wt} \%$ of PMo12. hybrid material. Generally, PAni prepared in a heterogeneous biphasic system, where polymerization occurs primarily at the interface shows fibrous morphology (Zhang et al 2004; Huang 2006; Xing et al 2008). The results obtained for hybrid materials synthesized in the absence of PMo12 shows as expected fibrous morphology which proves the reliability of the adopted procedure (figure 4a). SEM images of obtained hybrid materials with different amounts of PMo12 (0.05-1 wt\%) are shown in figure $4(\mathrm{~b}-\mathrm{f})$. When the PMo12 concentration is increased $(0.05-0.25 \mathrm{wt} \%)$, size of the fibre gets decreased and the clustered polymers are obtained. On further increase in concentration of PMo12 (0.5 wt\%) resulted in nearly spherical-shaped hybrid polymer, which may be due to the negatively charged PMo12 acting as supermolecular aggregates to direct the growth of polyaniline. When the concentration of PMo12 is raised further to $1 \mathrm{wt} \%$, it results in the hybrid material in a defined spherical structure. To authenticate the presence of PMo12 in the synthesized hybrid materials, energy dispersive X-ray (EDX) analysis was recorded, which clearly shows the peaks for elemental components of PMo12 (see inset of figure $4 \mathrm{f}$ ).

The thermal stability of the interfacially synthesized PAni-PMo12 hybrid materials with different amounts of PMo12 (0-1 wt\%) were analysed by recording TGA/DTA profiles (figure 5). TGA curves of polyaniline without PMo12 (figure 5a) shows decrease of mass about $10 \%$ within the temperature range of $60-200{ }^{\circ} \mathrm{C}$. The observed weight changes in this region are associated with expulsion of adsorbed solvents and water from the samples. Further, after a slight weight loss, it becomes relatively steady in the temperature region of $200-340{ }^{\circ} \mathrm{C}$ (about 22\%). Added increase in temperature results in the gradual decomposition of polymer backbone and overall $96 \%$ weight loss was attained at $700{ }^{\circ} \mathrm{C}$. We obtained relatively similar behaviour for all PMo12 loaded samples up to $200{ }^{\circ} \mathrm{C}$ and were extremely stable up to $340{ }^{\circ} \mathrm{C}$. As thermal stability of PMo12 depends on the environment and the matrix present, PMo12-doped PAni hybrid materials did not show characteristics of parent phosphomolybdic acid and resembled the thermal curve of pure PAni. It could be seen from all the TGA profiles that the weight loss of hybrid materials at $340{ }^{\circ} \mathrm{C}$ is decreased with increase in PMo12 content. An observed weight loss of $22 \%$ has been observed for PMo12 free samples, whereas only $8 \%$ weight loss has been observed for $1 \mathrm{wt} \%$ PMo12 loaded sample. Beyond $340{ }^{\circ} \mathrm{C}$, the rapid decomposition of hybrid materials and associated phase transition of PMo12 will occur simultaneously. It is understood from the literature (Uma and Nogami 2007) that the decomposition of pure PMo12 will occur through the removal of constitutional water, which could be removed above $200{ }^{\circ} \mathrm{C}$.

$$
\mathrm{H}_{3} \mathrm{PMo}_{12} \mathrm{O}_{40} \rightarrow 1 / 2 \mathrm{P}_{2} \mathrm{O}_{5}+12 \mathrm{MoO}_{3}+3 / 2 \mathrm{H}_{2} \mathrm{O} \text {. }
$$



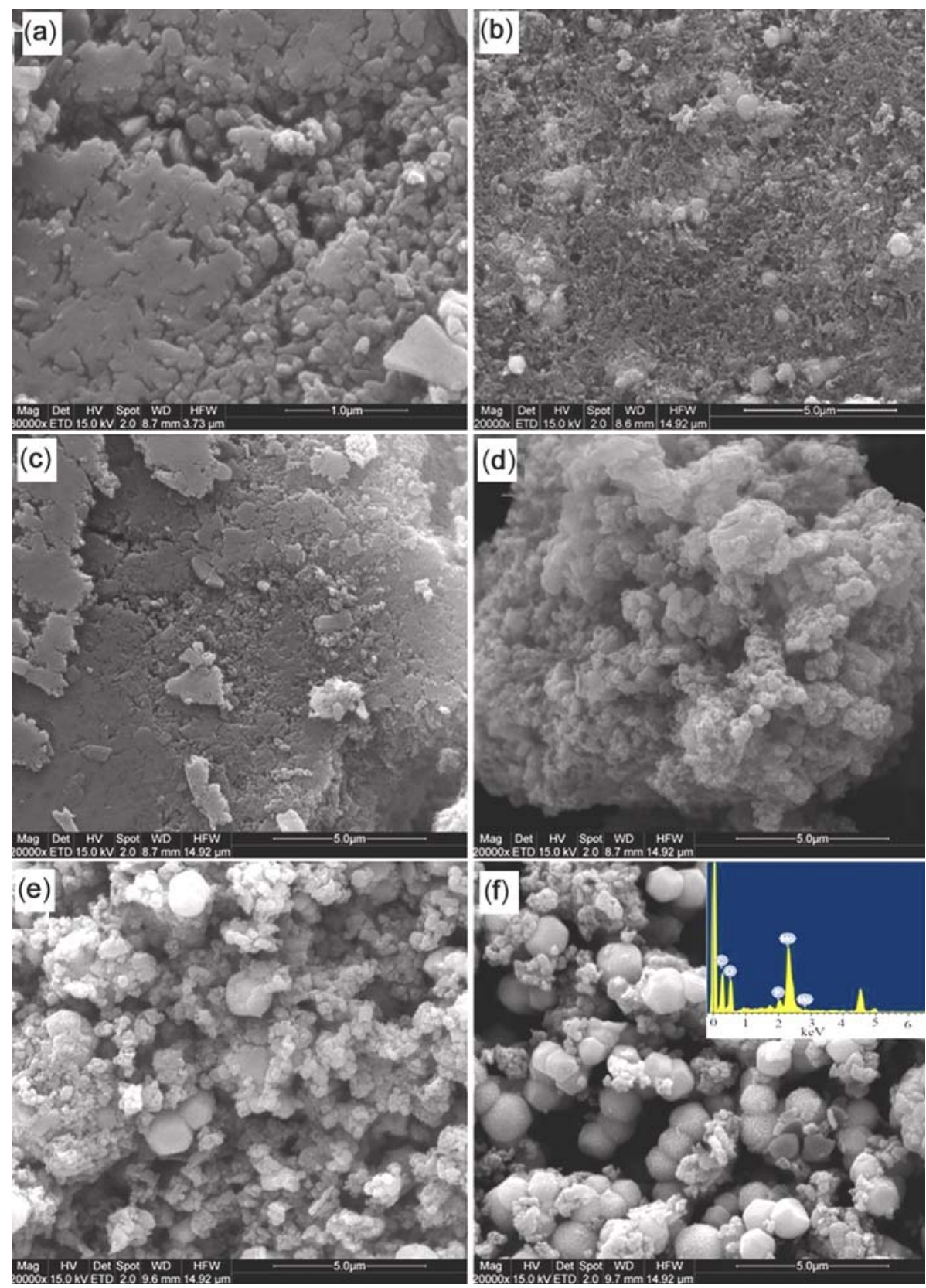

Figure 4. SEM images of interfacially synthesized PAni-PMo12 hybrid materials at different concentrations of PMo12 (a-f) $=0,0 \cdot 05,0 \cdot 1,0 \cdot 25,0.5$ and $1 \mathrm{wt} \%$ of PMo12; inset of figure 4(f) shows the corresponding EDX spectrum.

DTA profiles of the synthesized PAni-PMo12 hybrid materials demonstrate two-step endothermic transitions. At low PMo12 concentrations, a broad endothermic peak around $400{ }^{\circ} \mathrm{C}$ was obtained which assumed to be the combined decomposition of PAni and PMo12. At higher PMo12 loading, two distinct endothermic peaks were observed around 350 and $420{ }^{\circ} \mathrm{C}$, which could be explained as decomposition of PAni-PMo12, followed by the phase transition of formed $\mathrm{MoO}_{3}$ moiety.

Further, the overall weight loss suffered by PAniPMo12 hybrid materials decreases, while increasing the concentration of PMo12. The synthesized PAni-PMo12 hybrid materials with $1 \mathrm{wt} \%$ PMo12 shows only $30 \%$ weight loss at $700{ }^{\circ} \mathrm{C}$, whereas the sample without PMo12 suffered 96\% weight loss. Thus, from TGA and DTA results, the presence of PMo12 and enhanced thermal stability of the hybrid materials were understood.

\subsection{Conductivity measurements}

The electrical conductivity is the most important property of PAni-based hybrid materials. Room temperature electrical conductivity of PAni-PMo12 hybrid materials were 
measured using the standard four-probe technique. Generally, doping of conducting polymers implies charge transfer, associated insertion of a counter ion and the simultaneous control of Fermi level or chemical potential (Kumari et al 2011). The electrical conductivity of conducting polymers results from mobile charge carriers introduced into $\pi$-electronic system through doping. The variation of electrical conductivity of PAni-PMo12 hybrid materials with different PMo12 concentrations (0, $0 \cdot 05,0 \cdot 1,0 \cdot 25,0.5$ and $1 \mathrm{wt} \%$ ) are shown in table 1 . The PAni prepared without PMo12 shows measured conductivity of $0.053 \mathrm{~S} \mathrm{~cm}^{-1}$. It is observed that with the increase in concentration of PMo12 from 0.05 to $0.5 \mathrm{wt} \%$, the conductivity of hybrid materials increases from 0.089 to $0.339 \mathrm{~S} \mathrm{~cm}^{-1}$. This is attributed to the fact that with the increase in dopant concentration, more conducting islands are formed within the hybrids that could increase the degree of crystallinity of the material due to decreased scattering of charge carriers. Further, increase in PMo12 wt\% results and drop in electrical conductivity which may be attributed to the unavailability of PAni backbones for doping. The observed increase in crystallinity is also consistent with the obtained XRD results.

\subsection{Electrochemical super capacitor studies}

The prepared PAni-PMo12 hybrid materials were evaluated as active electrode material for supercapacitor application. The cyclic voltammetric responses of stainless steel (SS) electrodes modified using PAni-PMo12 hybrid materials with different amounts of PMo12 (0-1 wt\%) were recorded at $20 \mathrm{mV} \mathrm{s}^{-1}$ in $1 \mathrm{M} \mathrm{H}_{2} \mathrm{SO}_{4}$ as electrolyte solution and are shown in figure 6. It was evident by broad redox peaks ascribed to the Faradaic reaction of PMo12, suggesting the pseudo-capacitive behaviour. The broad cyclic voltammograms involving a higher current

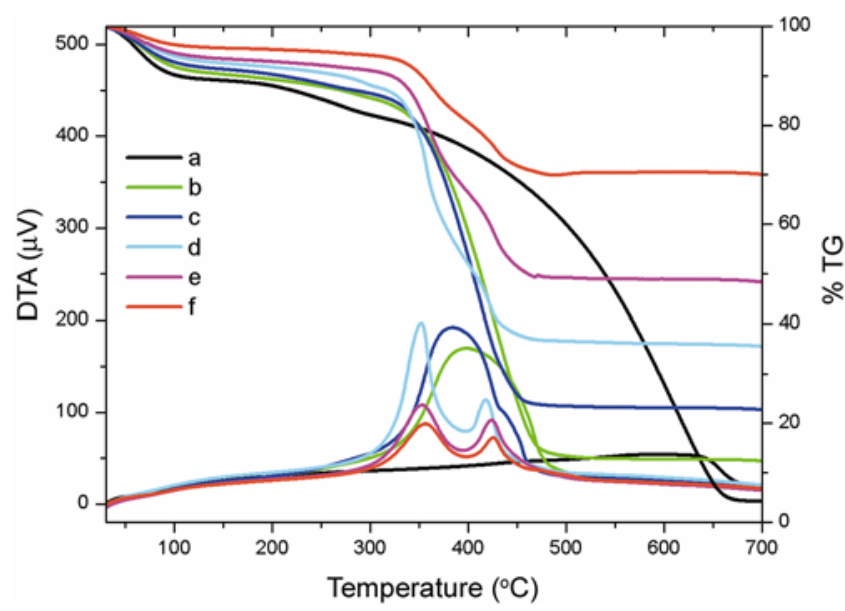

Figure 5. Thermal analysis of interfacially synthesized PAniPMo12 hybrid materials at different concentrations of PMo12; $(\mathrm{a}-\mathrm{f})=0,0 \cdot 05,0 \cdot 1,0 \cdot 25,0.5$ and $1 \mathrm{wt} \%$ of PMo12. suggested that the PAni-PMo12 hybrid materials could be a useful material for electrochemical supercapacitors. The quasi-rectangular shape that could be fit into the cyclic voltammogram also indicated a supercapacitor nature (inset of figure 6). This behaviour of parallelogram $\mathrm{CV}$ shape represents the rapid response of current to change of potential, which is essential to ensure optimum energy storage during fast charge-discharge processes. CV profiles of all the hybrid-modified SS electrodes are also recorded at different scan rates (figure not shown). When the scan rate was increased, the current was also increased and the shapes of the curves are nearly rectangular indicating the excellent capacitive behaviour and low contact resistance in the supercapacitor electrode.

Finally, the electrodes were subjected to chargedischarge tests in the potential range from 0.0 to $0.75 \mathrm{~V}$ at an applied current density of $1 \mathrm{~mA} \mathrm{~cm}^{-1}$. Both the linear profile of charge and discharge curves (figure 7a-f) exhibit good electrochemical reversibility without apparent deviations in each cycle reveal good capacitive characteristics of the hybrid electrode. The specific capacitance $\left(C_{\mathrm{sp}}\right)$ values were calculated from discharge times using the following (2)

$$
C_{\mathrm{sp}}=\frac{i t}{\Delta V m},
$$

where $i$ is the current density, $t$ the discharge time in seconds, $\Delta V$ the potential window and $m$ the mass of the electro-active material.

The supercapacitor electrode prepared using interfacially prepared PAni without PMo12 shows specific

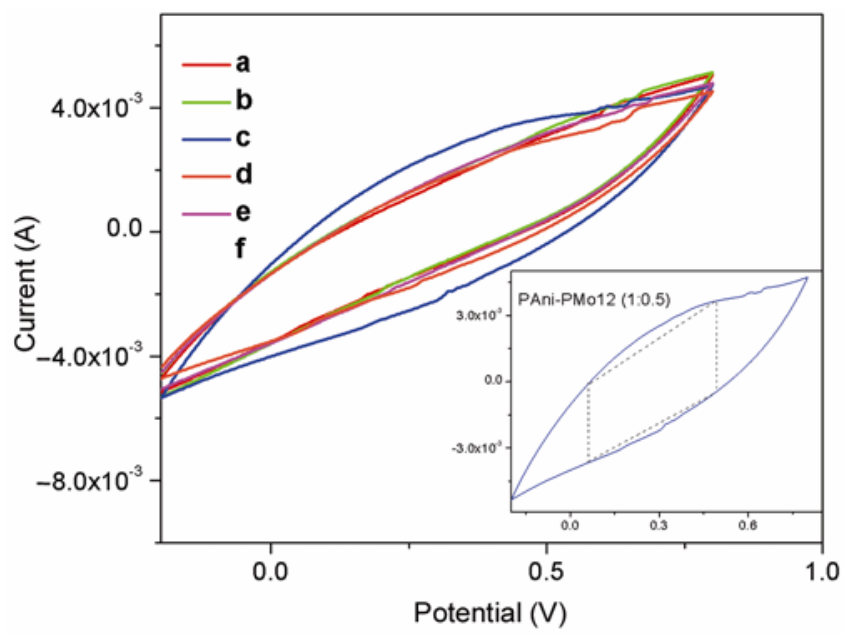

Figure 6. Cyclic voltammetric behaviour of super-capacitor electrode fabricated with interfacially synthesized PAni-PMo12 hybrid materials at different concentrations of PMo12; $(\mathrm{a}-\mathrm{f})=0,0.05,0.1,0.25,0.5$ and $1 \mathrm{wt} \%$ of PMo12 were recorded at $20 \mathrm{mV} \mathrm{s}^{-1}$ in $1 \mathrm{M} \mathrm{H}_{2} \mathrm{SO}_{4}$ as electrolyte solution. Inset shows fitted parallelogram shape in cyclic voltammetric behaviour. 
Table 1. Electrical conductivity and specific conductance of interfacially synthesized PAni-PMo12 hybrid materials at different concentrations of PMo12.

\begin{tabular}{lcccc}
\hline $\begin{array}{l}\text { Sl. } \\
\text { No. }\end{array}$ & $\begin{array}{c}\text { Concentration of } \\
\text { PMo12 (wt\%) }\end{array}$ & $\begin{array}{c}\text { Mass of active } \\
\text { material }\left(10^{-1} \mathrm{~g}\right)\end{array}$ & $\begin{array}{c}\text { Conductivity } \\
\left(\mathrm{S} \mathrm{cm}^{-1}\right)\end{array}$ & $\begin{array}{c}\text { Specific capacitance } \\
\left(\mathrm{F} \mathrm{g}^{-1}\right)\end{array}$ \\
\hline 1 & 0 & $3 \cdot 1$ & $0 \cdot 053$ & $68 \cdot 82$ \\
2 & $0 \cdot 05$ & $2 \cdot 9$ & $0 \cdot 089$ & $81 \cdot 38$ \\
3 & $0 \cdot 1$ & $3 \cdot 1$ & $0 \cdot 149$ & $102 \cdot 14$ \\
4 & $0 \cdot 25$ & $2 \cdot 9$ & $0 \cdot 255$ & $126 \cdot 44$ \\
5 & $0 \cdot 5$ & $2 \cdot 8$ & $0 \cdot 339$ & $172 \cdot 38$ \\
6 & 1 & $3 \cdot 2$ & $0 \cdot 091$ & $70 \cdot 00$ \\
\hline
\end{tabular}
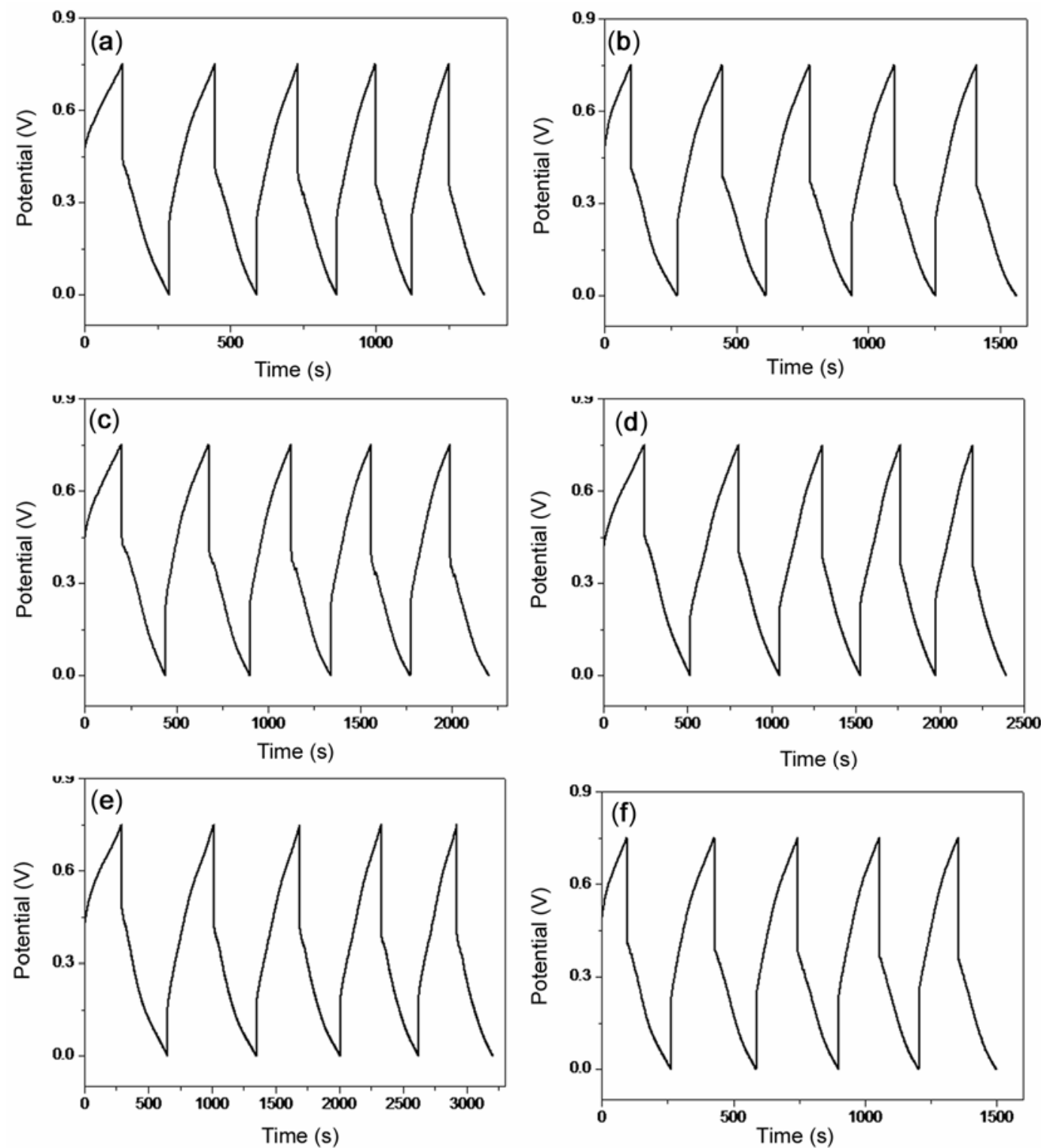

Figure 7. Typical galvanostatic charge-discharge profile of supercapacitor electrode fabricated using interfacially synthesized PAni-PMo12 hybrid materials with different amounts of PMo12; $(\mathbf{a}-\mathbf{f})=0$, $0 \cdot 05,0 \cdot 1,0 \cdot 25,0.5$ and $1 \mathrm{wt} \%$ of PMo12. Current density $=1 \mathrm{~mA} / \mathrm{cm}^{2}$.

capacitance of $68.82 \mathrm{Fg}^{-1}$. These specific capacitance values are in agreement with those reported in the literature for pure PAni films (Radhakrishan et al 2009a,b).
The hybrid-modified electrodes, prepared with incorporation of PMo12 in PAni shows relatively higher specific capacitance values which increases with increase in the 
concentration of PMo12 (see table 1) and attained the maximum value of $172.38 \mathrm{~F} \mathrm{~g}^{-1}$ for $0.5 \mathrm{wt} \%$ PMo12loaded hybrid. This indicates a synergistic effect from the combined contributions of PMo12 and PAni. That is, the redox reactions from PMo12 contribute pseudocapacitance to the total capacitance apart from the double layer capacitance from PAni. Supercapacitor electrodes benefit not only from the Faradaic contribution of both components, but also by the presumed homogeneity of the distribution of PMo12 ions, a condition that leads to greater charge delocalization and enhanced conductivity and thus, enhanced specific capacitance. However, when the ratio of PMo12 further increases from 0.5 to $1 \mathrm{wt} \%$, the capacitor behaviour deteriorates and the specific capacitance of that hybrid electrode degrades dramatically to around $70 \mathrm{~F} \mathrm{~g}^{-1}$, still higher than that of pure PAni. This is because a large amount of PMo12 covering the PAni destroys the network structure of PAni matrix and lowers conductivity of the electrode. Generally, the specific capacitance of PAni-based electrochemical capacitors essentially depends on mass, conductivity and morphology of the active material present in the electrode (Inamdar et al 2011). As the same mass of active materials were used for preparing supercapacitor electrode, the conductivity of the materials plays an important role in the PMo12-loaded samples. The electrical conductivity measurements also support the trend obtained from galvanostatic charge-discharge studies that is in accordance with cyclic voltammetric studies.

\section{Conclusions}

A facile interfacial polymerization approach was exploited to synthesize PAni-PMo12 hybrid materials. This process has offered a simple and reliable route to prepare conducting polymer-based hybrid materials with different amounts of PMo12 loading. The formation of the hybrid PAni-PMo12 materials was confirmed by FT-IR, UV-Vis and XRD analysis. Physicochemical properties with respect to the concentration of PMo12 were discussed. The observed thermal stability of PAni-PMo12 hybrid suggested that PMo12 has benefitted from the thermal stability of PAni support. Uniform distribution of surface morphology was observed from scanning electron microscopic studies, and further change in morphology from fibrous to almost spherical structure was noticed for the hybrid prepared without and with PMo12, respectively. The hybrid materials were examined as the electrode material for supercapacitor application. The conductivity, cyclic voltammetry and galvanostatic charge-discharge studies suggested that the $0.5 \mathrm{wt} \%$ PMo12 loading was found to be a relatively better combination in terms of enhanced conductivity and capacitance characteristics and could be evolved as the electrode material for supercapacitor applications.

\section{Acknowledgement}

One of the authors (SA) thanks DST, New Delhi, for the sanction of India-Spain collaborative research grant (DST/INT/Spain/P-37/11, 16 December 2011).

\section{Electronic Supplementary Material}

Supplementary material pertaining to this article is available on the Bulletin of Materials Science website (www.ias.ac.in/matersci).

\section{References}

Bhadra S, Khastgir D, Singha N K and Lee J H 2009 Prog. Polym. Sci. 34783

Chiang J C and MacDiarmid A G 1986 Synth. Met. 13193

Choi J, Kim Y, Lee J, Cho K, Jung H, Park J, Park I and Sung Y 2005 Solid State Ionics 1763031

Colomban P A, Cruger A, Novak A and Regis A $1994 \mathrm{~J}$. Mol. Struct. 317261

Cuentas-Gallegos A K, Martinez-Rosales R, Baibarac M, Gomez-Romero P and Rincon M E 2007 Electrochem. Commun. 92088

de Leeuw D M, Simenon M M J, Brown A R and Einerhand R E F 1997 Synth. Met. 8753

Dolbecq A, Dumas E, Mayer C R and Mialane P 2010 Chem. Rev. 1106009

Emmanuel F, Chimamkpam C, Hussain F, Engel A, Schilling A and Patzke G R 2009 Z. Anorg. Allg. Chem. 635624

Fan D, Li G and Hao J 2010 J. Colloid Interf. Sci. 351151

Fauziah S, Draman S, Daik R and Ahmad M 2009 Malaysian Polym. J. 47

Ganesan R and Gedanken A 2008 Nanotechnology 19435709

Ghadimi F, Safa K D, Massoumi B and Entezami A 2002 Iranian Polym. J. 11159

Gharibi H, Zhiani M, Entezami A, Abdullah Mirzaie R, Kheirmand M and Kakaei K 2006 J. Power Sources 155138

Gharibi H, Kakaei K, Zhiani M and Taghiabadi M 2011 Int. J. Hydrogen Energy 3613301

Gong J, Cui X J, Wang S G, Lun Z X and Qu Y 2002 Chin. Chem. Lett. 13123

Gomez-Romero P, Chojak M, Cuentas-Gallegos K, Asensio J A, Kulesza P J, Casa Pastor N and Cantu M L 2003 Electrochem. Commun. 5149

Gurunathan K and Trivedi D C 2000 Mater. Lett. 45262

Gurunathan K, Amalnerkar D P and Trivedi D C 2003 Mater. Lett. 571642

Hasik M, Paluszkiewicz C and Wenda E 2002 Vib. Spectrosc. 29191

Huang J 2006 Pure Appl. Chem. 7815

Huang Y F, Lin C W, Chang C S and Ho M J 2011 Electrochim. Acta 565679

Inamdar A I, Kim Y S, Sohn J S and Im H 2011 J. Korean Phys. Soc. 59145

Kulesza P J, Karnicka K, Miecznikowski K, Chojak M, Kolary A, Barczuk P J, Tsirlina G and Czerwinski W 2005 Electrochim. Acta 505155 
Kumari K, Ali V, Kumar A, Kumar S and Zulfequar M 2011 Bull. Mater. Sci. 341237

Lira-Cantu M and Gomez-Romero P 1998 Chem. Mater. 10698

Mahanta D, Munichandraiah N, Radhakrishnan S, Madras G and Patil S 2011 Synth. Met. 161659

Malinauskas A 2001 Polymer 423957

Manivel A and Anandan S 2011 J. Solid State Electrochem. 15 153

Matsuguchi M and Asahi T 2011 Sens. Actuators B: Chem. 160 999

Nisar A, Lu Y and Wang X 2010 Chem. Mater. 223511

Otero T F, Cheng S A and Huerta F 2000 J. Phys. Chem. B104 10522

Palaniappan S 2001 Eur. Polym. J. 37975

Radhakrishnan S, Prakash S, Rao C R K and Vijayan M 2009a Electrochem. Solid State Lett. 12 A84

Radhakrishan S, Rao C R K and Vijayan M 2009b J. Appl. Polym. Sci. 1143125

Radhakrishnan S, Rao C R K and Vijayan M 2011 J. Appl. Polym. Sci. 1221510
Ryu K, Chang S H, Kang S, Oh E J and Yo C H 1999 Bull. Korean Chem. Soc. 20333

Sanchez C, de G J Soler-Illia A A, Ribot F, Lalot T, Mayer C R and Cabuil V 2001 Chem. Mater. 133061

Sanchez C, Julian B, Belleville P and Popall M 2005 J. Mater. Chem. 153559

Sanchez C, Rozes L, Ribot F, Laberty-Robert C, Grosso D, Sassoye C, Boissiere C and Nicole L 2010 CR Chim. 133

Sine G, Hui C C, Kuhn A, Kulesza P J, Miecznikowski K, Chojak M, Paderewska A and Lewera A 2003 J. Electrochem. Soc. 150 C351

Tang J, Jing X, Wang B and Wang F 1988 Synth. Met. 24 231

Uma T and Nogami M 2007 Chem. Mater. 193604

White A M and Slade R C T 2003 Electrochim. Acta 48 2583

Xing S, Zheng H and Zhao G 2008 Synth. Met. 15859

Zhang X, Chan-Yu-King R, Jose A and Manohar S K 2004 Synth. Met. 14523 